\title{
Plasma concentration of brominated flame retardants and postmenopausal breast cancer risk: a nested case-control study in the French E3N cohort
}

Francesca Romana Mancini ${ }^{1,2^{*}}$ (D) German Cano-Sancho ${ }^{3}$, Oceane Mohamed ${ }^{1,2}$, Iris Cervenka ${ }^{1,2}$, Hanane Omichessan ${ }^{1,2}$, Philippe Marchand ${ }^{3}$, Marie-Christine Boutron-Ruault ${ }^{1,2}$, Patrick Arveux ${ }^{1,2,4}$, Gianluca Severi ${ }^{1,2,5}$, Jean-Philippe Antignac ${ }^{3}$ and Marina Kvaskoff ${ }^{1,2}$

\begin{abstract}
Background: Brominated flame retardants (BFRs) are lipophilic substances with endocrine-disrupting properties. To date, only few investigations, mainly retrospective case-control studies, have explored the link between internal levels of BFRs and the risk of breast cancer, leading to conflicting results. We investigated the associations between plasma concentrations of two main groups of BFRs, PBDEs (pentabromodiphenyl ethers) and PBBs (polybrominated biphenyls), and the risk of breast cancer in a nested case-control study.

Methods: A total of 197 incident breast cancer cases and 197 controls with a blood sample collected in 1994-1999 were included. Plasma levels of PBDE congeners (BDE-28, BDE-47, BDE-99, BDE-100, BDE153, BDE-154) and of PBB153 were measured by gas chromatography coupled to high-resolution mass spectrometry. Conditional logistic regression models, adjusted for potential confounders, were used to estimate odds ratios (ORs) and 95\% confidence intervals (Cls).

Results: Women were aged 56 years on average at blood draw. All cases, except for one, were diagnosed after menopause, with an average age at diagnosis of 68 years. Overall, we found no evidence of an association between plasma levels of PBDEs and PBB-153 and postmenopausal breast cancer risk (log-concentrations of BFRs yielding non-statistically significant ORs of 0.87 to 1.07). The analysis showed a non-linear inverse association for BDE-100 and BDE-153 and postmenopausal breast cancer risk; nevertheless, these findings were statistically significant only when the exposure was modeled as ng/L plasma (third vs. first quintile: $\mathrm{OR}=0.42,95 \% \mathrm{Cl}=0.19-0.93$ and $\mathrm{OR}=0.42$, $95 \% \mathrm{Cl}=0.18-0.98$, respectively) and not when modeled as $\mathrm{ng} / \mathrm{gr}$ of lipids $(\mathrm{OR}=0.58,95 \% \mathrm{Cl}=0.27-1.25$ and $\mathrm{OR}=$ $0.53,95 \% \mathrm{Cl}=0.25-1.17)$. These results were unchanged in stratified analyses by tumor hormone receptor expression or body mass index.

\footnotetext{
* Correspondence: Francesca.mancini@gustaveroussy.fr

${ }^{1}$ CESP, Faculté de médecine, Université Paris-Saclay, UVSQ, INSERM, Villejuif,

France

${ }^{2}$ Gustave Roussy, Villejuif, France

Full list of author information is available at the end of the article
}

(c) The Author(s). 2020 Open Access This article is licensed under a Creative Commons Attribution 4.0 International License, which permits use, sharing, adaptation, distribution and reproduction in any medium or format, as long as you give appropriate credit to the original author(s) and the source, provide a link to the Creative Commons licence, and indicate if changes were made. The images or other third party material in this article are included in the article's Creative Commons licence, unless indicated otherwise in a credit line to the material. If material is not included in the article's Creative Commons licence and your intended use is not permitted by statutory regulation or exceeds the permitted use, you will need to obtain permission directly from the copyright holder. To view a copy of this licence, visit http://creativecommons.org/licenses/by/4.0/. The Creative Commons Public Domain Dedication waiver (http://creativecommons.org/publicdomain/zero/1.0/) applies to the data made available in this article, unless otherwise stated in a credit line to the data. 


\begin{abstract}
(Continued from previous page)
Conclusions: Our results suggest no clear association between internal levels of PBDEs and PBB-153 and the risk of breast cancer in postmenopausal women. However, these findings need to be carefully interpreted, taking into account limitations due to the limited number of women included in the study, the lack of information concerning genetic susceptibility of cases, and the unavailability of exposure assessment during critical windows of susceptibility for breast cancer. More studies are warranted to further investigate the relationships between PBDE and PBB exposure and breast cancer risk.
\end{abstract}

Keywords: Breast cancer, Brominated flame retardants (BFRs), Pentabromodiphenyl ethers (PBDEs), Polybrominated biphenyls (PBBs), E3N cohort, Biomonitoring

\section{Introduction}

Despite a large body of research, the etiology of breast cancer has not yet been fully delineated, as established risk factors cannot solely explain the increased incidence reported worldwide. In Europe, breast cancer is the most common cancer in women with an incidence of 60 to 155 cases per 100,000 [1]. The main known risk factors for breast cancer include non-modifiable risk factors - such as age, early menarche, late menopause, family history of breast cancer, and genetic mutations (e.g. mutations in the $B R C A 1$ and BRCA2 genes) - and modifiable risk factors such as use of hormonal treatments, alcohol consumption, tobacco smoking, overweight, and lack of physical activity, [2]. Nevertheless, it has been estimated that less than 25\% of breast cancers are attributable to the main modifiable risk factors and between 10 and 30\% to hereditary factors $[3,4]$. There is growing concern that exposure to chemical environmental contaminants, particularly endocrinedisrupting chemicals (EDCs), could be one of the factors that led to an increased incidence of breast cancer in the Western world [5].

Brominated flame retardants (BFRs) are lipophilic substances present as a mixture of congeners in several consumer products to make them less flammable. Produced since the early 1960s, their use has been progressively limited and banned in Europe during the 90s when the production reached the levels of 33,000 metric tonnes in 1994 [6]. PBBs were first restricted by the 4th amendment to the marketing and use Directive 76/769/EEC adopted in 1984 and in 2000 the production was voluntarily ceased by the industry [7]. Commercial mixtures Penta- and Octa-PBDE products were first restricted in 1976 under the Directive 76/769/ECC and banned in 2003 in concentrations higher than $0.1 \%$ by mass [8]. Nevertheless, due to their resistance to degradation, BFRs are widespread in the environment, even in areas located remotely from sites of production or use [9]. Diet has been identified as the main source of exposure to BFRs for adults, although the exposure can also be related to other routes such as inhalation or dermal absorption as a consequence of their accumulation in indoor dust [10]. Unfortunately, the long-term toxic effects of these BFRs in humans are not completely known, although they are suspected to act as EDCs, since a link between exposure to BFRs and several endocrine-related diseases has been reported [11]. In 2019, PBDEs, one of the major groups of BFRs, have been included in the high-priority list of agents not previously evaluated by the International Agency for Research on Cancer (IARC) Monographs on the basis of relevant bioassay and mechanistic evidence [12].

There is increasing interest in understanding the contribution of BFRs to breast cancer incidence; nevertheless, evidence of an association between environmental exposure to these chemicals and breast cancer risk is still inadequate to draw firm conclusions $[5,13]$. To date, only few studies have investigated the link between internal levels of BFRs and the risk of breast cancer, with inconsistent results. To the best of our knowledge, regarding PBDE, all available studies followed a retrospective case control study design [14-17], while for PBB the available studies were case-control studies nested in a prospective cohort [18-20]. Finally, all the currently available studies have been conducted in the US [14-16, 18-20] or in China [17], and none was performed in Europe.

Our objective was to prospectively investigate the associations between plasma concentrations of two main groups included in the family of BFRs, PBDEs and PBBs, and the risk of postmenopausal breast cancer in women in a case-control study nested in the French E3N cohort.

\section{Methods}

\section{The E3N study}

E3N (Etude Epidémiologique auprès de femmes de l'Education Nationale) is a prospective cohort study involving 98,995 French women, aged 40-65 years at inclusion in 1990 and insured by a national health insurance covering workers from the French National Education System (Mutuelle Générale de l'Education Nationale, MGEN) [21]. Participants were enrolled after completing a baseline self-administered questionnaire and returning a 
signed informed consent. Follow-up questionnaires were sent every 2-3 years thereafter. Detailed cancer risk factor data were collected through questionnaires at different time points during follow-up, including reproductive history, use of hormonal treatments, anthropometric characteristics, smoking habits, alcohol consumption, diet, and physical activity. The average follow-up rate per questionnaire cycle has been of $83 \%$, and to date, the total loss to follow-up since 1990 has been $<3 \%$. The study was approved by the French National Commission for Data Protection and Privacy.

Between 1994 and 1999, E3N participants were invited to donate blood, resulting in the collection of blood samples from approximately 25,000 participants. Each sample was separated into 28 aliquots (i.e. plasma, serum, buffy-coat, leukocytes, and erythrocytes) that were stored in plastic straws in liquid nitrogen containers $\left(-196^{\circ} \mathrm{C}\right)$ in a biobank.

Breast cancer cases were identified through selfreport in the questionnaires, from the MGEN files, or through information from death certificates. Deaths were reported by family members and by searches in the MGEN files, and causes of death were obtained from the National Death Index. Pathology reports were obtained for $93 \%$ of incident cases. We also considered cases for which pathology reports have not been obtained, because the proportion of falsepositive self-reports was low in our study population $(<5 \%)$. Cases were identified up to 2013 , which was therefore used as the date of end of follow-up in statistical analyses.

\section{The nested case-control study on breast cancer}

As previously described [22], 281 breast cancer cases for which at least 3 aliquots of serum and 6 aliquots of plasma were available in the biobank were identified among the E3N population. From these, all cases who had not completed the dietary questionnaire in 1993 $(n=27)$ or who were diagnosed before blood sampling and/or before returning the dietary questionnaire were excluded $(n=11)$. Cases of Paget's disease and benign breast disease were also excluded $(n=3)$. Finally, 240 incident breast cancer cases were available. Due to budget constraints, among those, 197 incident breast cancer cases (174 invasive and 23 in situ) were randomly selected and included in the study.

For each case, one control was sampled from women who were free of breast cancer at the time of diagnosis of the corresponding case (density sampling method). Controls were matched to cases by age ( \pm 2 years), menopausal status (premenopausal or postmenopausal), body mass index (BMI) $\left(<25\right.$ or $\left.\geq 25 \mathrm{~kg} / \mathrm{m}^{2}\right)$, all at blood collection, and year of blood collection.

\section{Measurement of biomarkers of exposure}

The methodologies applied to isolate, detect, and quantify the PBDE congeners (BDE-28, BDE-47, BDE-99, BDE-100, BDE-153, BDE-154) and PBB-153 have been published elsewhere [23, 24]. Briefly, plasma samples were first submitted to a liquid/liquid extraction with pentane. Resulting extracts were weighed to measure fat content using an enzymatic method (Biolabo,Maizy, France), and reconstituted in hexane for further purification. The determinations were performed by gas chromatography (Agilent 7890A) coupled to high-resolution mass spectrometry (GC-HRMS) on double sector instruments (JEOL MS 700D and 800D) after electron impact ionization $(70 \mathrm{eV})$, operating at 10,000 resolutions $(10 \%$ valley) and in the single ion monitoring (SIM) acquisition mode. All the analyses have been conducted in an ISO 17025:2005 accredited laboratory. The limits of detection (LOD) were $0.03 \mathrm{ng} / \mathrm{L}$ for BDE-28, $0.02 \mathrm{ng} / \mathrm{L}$ for BDE-154, and $0.1 \mathrm{ng} / \mathrm{L}$ for BDE-47, BDE-99, BDE-100, BDE-153 and PBB-153. To ensure the quality of the analysis, besides the appropriate use of internal standards in each sample, ${ }^{13} \mathrm{C}_{12}$ labelled standards were added at the end of each clean-up process in order to calculate recoveries that ranged between 60 and 120\%. The accuracy was determined according the ISO 17025 requirements, setting up the lower spiking level at $0.5 \mathrm{ng} / \mathrm{L}(n=5)$, being the trueness within the range between 3\% (BDE-99) and 37\% (BDE-28), and the precision ranged between 13\% (BDE-47) and 28\% (PBB153). The analytical performance was considered acceptable for all congeners; however, it should be noted the analytical uncertainty associated to lower concentrations for BDE28. Moreover, cleaned laboratory glassware was rinsed with dichloromethane prior to use and the analyses were carried out in an over-pressurized room to minimize environmental contamination followed by a continuous monitoring of the analytical procedure implemented through procedural blanks [25]. The blank controls were not deducted because of the absence of analytical contamination. The accuracy of the analytical method was further ensured by regular participation of the laboratory to proficiency tests organized by the European Reference Laboratory (EURL) for POPs. The total plasma lipid (TPL) levels were calculated by using the Akins formula, combining the concentration of phospholipids ( $\mathrm{PHO})$, triacylglycerides (TAG), total cholesterol (t.CHO) and free cholesterol (f.CHO) as follows: TPL $=1.677^{*}($ t.CHO-f.CHO $)+$ f.CHO + TAG+PHO) [26].

\section{Statistical analysis}

In all statistical analyses, values below the limit of detection (LOD) were substituted with the equivalent of $1 / 2 \mathrm{LOD}$. Kruskal-Wallis tests were performed to compare concentrations of PBDEs and PBB-153 between cases 
and controls. Spearman rank correlation tests were performed to determine correlation structures between plasma concentrations of PBDEs and PBB-153.

Conditional logistic regression models were used to estimate odds ratios (ORs) and 95\% confidence intervals (CIs) of breast cancer in relation to plasma concentration levels of PBDEs and PBB-153 expressed as ng/L plasma. We also used conditional logistic regression models using both the exposure variable as a continuous variable, after log-transformation, and as a categorical variable, dividing it into quintile groups based on plasma concentrations of PBDEs and PBB-153 in controls. When considering the exposure as a categorical variable, tests for linear trend were performed by assigning the median value to each quintile group and by modeling these values as continuous variables. For all adjustment variables, we considered the value collected in the last questionnaire available before the date of diagnosis in cases. All analyses were performed for each substance separately and for the sum of concentrations of PBDEs. An unadjusted model (Model 0) was fitted, as well as three adjusted models with an increasing number of covariates. Model 1 was adjusted for total plasma lipid content by the addition of a separate term in the model (ng/L, continuous), as recommended by Schisterman et al. [27]. Model 1 was further adjusted for smoking status (never vs. ever), physical activity measured in metabolic equivalent tasks (MET)-hour/week ( $<35$ vs. $\geq 35$ ), education ( $\leq 12$ years, 12 to 14 years, $>14$ years), personal history of benign breast disease (no vs. yes), and family history of breast cancer (none, in first-degree relatives, in extended relatives), parity and age at first fullterm pregnancy (FFTP) (no children, 1 or 2 children and $<30$ years old at FFTP, $\geq 3$ children and $<30$ years old at FFTP, $\geq 30$ years old at FFTP), total breastfeeding duration (never, $\leq 6$ or $>6$ months), age at menarche $(<$ 13 years vs. $\geq 13$ years), current use of menopausal hormone therapy (pre-menopausal, yes, no), use of oral contraceptives (ever vs. never), menopausal status and age at menopause (pre-menopausal, menopause before age 51, menopause at age 51 or later). Finally, Model 2 was further adjusted for adherence scores to the Healthy and the Western dietary patterns (above vs. below the median), both derived using principal component analysis, as previously described [28]. The selection of confounders was done a priori, based on the known breast cancer risk factors available in our dataset that are potentially associated with exposure to PBDEs and PBB153.

Using multinomial regression, stratified analyses were performed based on tumor expression of estrogen (ERvs. $\mathrm{ER}+$ ) and progesterone (PR- vs. $\mathrm{PR}+$ ) receptors including all variables used in Model 2. Since multinomial regression models do not consider the case-control matching, multinomial models were additionally adjusted for the matching criteria: age at blood draw (continuous), BMI at blood draw (continuous), and year of blood draw (continuous), except for menopausal status at blood draw, in order to avoid over-adjustment considering the a priori inclusion of age at menopause in the model (premenopausal, postmenopausal and age at menopause < 51 years, postmenopausal and age at menopause $\geq 51$ years). All subjects for whom the information on hormone receptors was not available were grouped as one "missing" category and inserted in the model.

In order to better understand the underlying association between lipids, BFRs and breast cancer, all analyses were repeated using concentrations of PBDEs and PBB expressed as ng/gr of lipids in the plasma.

Finally, the analyses were repeated excluding the case diagnosed before menopause and her matched control.

\section{Sensitivity analysis}

Other authors highlighted that the evolution of body size over lifetime may have an impact of the risk of developing breast cancer [29]. On the other hand, because of the high lipophilicity of BFRs, it has been hypothesized that changes in body weight prior to blood sampling may partly explain circulating levels of BFRs, and that their absorption, distribution, metabolism, and excretion can be influenced by the evolution of body size [30]. In order to test this, we built two additional models in a sensitivity analysis. First, Model 2 was additionally adjusted for the evolution of women's body size between ages 8 and 35 years: the evolution trajectories of body size were determined from the 8 somatotypes of Sorensen reported by the women at recruitment [31]. The women reported which somatotypes best reflected their body size at different periods in life ("around 8 years old", "at puberty", "around 20-25 years old", "around 3035 years old"). Using the PROC TRAJ of SAS 9.3, we highlighted three trajectories of evolution of the body size of each woman using age as time scale: normal body size from ages 8 to 35 years; normal body size until puberty, followed by a large body size afterwards; and large body size from ages 8 to 35 years. All women were included in these trajectories.

Then, Model 2 was adjusted for BMI variation over the 5 years preceding blood sampling (BMI decrease of more than 2 points; stable BMI; and BMI increase of more than 2 points).

We conducted a stratified analysis based on BMI, considering groups with $\mathrm{BMI}<25$ and $\geq 25 \mathrm{~kg} / \mathrm{m}^{2}$.

In our study population, missing values were $<5 \%$ for all variables and were imputed to the median (continuous variables) or modal value (categorical variables). 
Statistical analyses were performed using the SAS software (version 9.4, SAS Institute). The threshold for statistical significance was set at $5 \%$. All statistical tests were two-sided.

\section{Results}

The main characteristics of the study population are presented in Table 1.

Quantifiable levels of PBDE-47, 99, 100, 153, and PBB153 were detected in all samples. BDE-28 was detected in all samples except for one control with a concentration below the LOD, while BDE-154 was below the LOD in 99 samples (46 cases and 53 controls), representing $25 \%$ of the study population. The highest concentration of BFR in the overall population was observed for BDE47 (median: $3.25 \mathrm{ng} / \mathrm{L}$ plasma; min-max: 0.39-82.65 ng/L plasma), while the lowest was observed for BDE-154 (median: $0.16 \mathrm{ng} / \mathrm{L}$ plasma; min-max: 0.03-3.76 ng/L plasma) (Table 2). Among PBDEs, we found high correlations between BDE-47, 99, 100, and 154, while BDE-28 and $\mathrm{BDE}-153$ had a more modest correlation with the other congeners; in contrast, PBB-153 was very weakly correlated with plasma levels of the PBDEs considered in this study, except for PBDE-153 with which a stronger correlation was observed (rho $=0.49)$ (Table 3$)$.

Mean age at breast cancer diagnosis was 68.4 years (range 54.3-84.9 years). All cases were diagnosed after menopause except for one. Information on tumor hormone receptor expression was available in 161 cases (82\%) for ER, and in 157 cases (80\%) for PR. In total, 135 tumors were $\mathrm{ER}+$ and 100 were $\mathrm{PR}+$.

When considering concentrations of PBDEs and PBB in $\mathrm{ng} / \mathrm{L}$ plasma as continuous variables, we did not find any statistically significant association between levels of PBDEs and PBB-153 and breast cancer risk. When considering these concentrations modeled in quintiles, we found no statistically significant association between the sum of PBDEs, BDE-28, 47, 99, 154, or PBB-153 and breast cancer risk in any of the models. In Models 1 and 2 , women in the 3rd quintile group of BDE-100 were at lower risk of breast cancer when compared with those in the 1st quintile group (Model 2: OR 0.42, 95\% CI 0.190.93). Similarly, when considering BDE-153, we observed a statistically significant inverse association with breast cancer risk for women in the 3rd quintile group when compared with those in the 1st quintile group in Models 1 and 2 (Model 2: OR 0.42, 95\% CI 0.18-0.98) (Table 4). After stratification based on hormone receptor status, there was a statistically significant inverse association only between the 3rd quintile group of BDE-153 and $\mathrm{ER}+$ breast cancer risk (OR 0.39, 95\% CI 0.16-0.93) although the number of cases included in the 3rd quintile group was limited (e.g. $12 \mathrm{ER}+$ and 4 ER- cases) (Tables S1 and S2).
When considering concentrations of PBDEs and PBB in ng/gr of lipids in the plasma both as continuous variables and in quintiles, we did not find any statistically significant association (Table 5). We also observed no statistically significant association after stratifying based on tumor expression of estrogen receptors, while we found a positive association between the 3rd quintile group of BDE-99 and PR- breast cancer risk (OR 3.13, 95\% CI 1.03-9.54) and an inverse association between women in the 2nd quintile group of PBB-153 and PR+ breast cancer risk (OR 0.34, 95\% CI 0.14-0.83) (Tables S3 and S4).

In a sensitivity analysis, we repeated the analyses after excluding the case diagnosed before menopause and her matched control, and the results remained unchanged (data not shown). In addition, compared to the main analyses, the results remained virtually unchanged in terms of magnitude and statistical significance in sensitivity analyses adjusting for the evolution of women's body size or BMI variation over the 5 years preceding blood sampling (data not shown).

In analyses stratified according to BMI $(<25$ and $\geq 25$ $\mathrm{kg} / \mathrm{m}^{2}$ ) and considering PBDE and PBB concentrations in $\mathrm{ng} / \mathrm{L}$ plasma, women in the 3rd quintile group of BDE-100 with a BMI $<25 \mathrm{~kg} / \mathrm{m}^{2}$ were at lower risk of breast cancer (OR 0.33, 95\% CI 0.12-0.90, compared with the 1 st quintile group). Among women with a BMI $\geq 25 \mathrm{~kg} / \mathrm{m}^{2}$, we found an inverse association with breast cancer risk among women in the 3rd quintile group of BDE-153 (OR 0.05, 95\% CI <0.00-0.62) and among those in the 3rd quintile group of PBB-153 (OR 0.13, 95\% CI < 0.02-0.87). On the other hand, when considering concentrations of PBDEs and PBB in ng/gr of lipids in the plasma, we observed a statistically significant inverse relationship only for the 2 nd and 3rd quintile groups of BDE-153 and only in women with a BMI $\geq 25$ $\mathrm{kg} / \mathrm{m}^{2}$ (OR 0.09, 95\% CI 0.01-0.08 and OR 0.07, 95\% CI 0.01-0.58, respectively) (Tables S5 and S6).

\section{Discussion}

In this nested case-control study of non-professionally exposed French women, we found no evidence of an association between plasma levels of PBDEs and PBB-153 and breast cancer risk, although when running the analyses with concentrations expressed as ng/L plasma, there was an inverse association between the 3rd quintile group of BDE-100 and BDE-153 and the risk of breast cancer.

To date, few studies have investigated the association between internal levels of PBDEs and PBB and breast cancer risk, and they led to inconsistent results. One study including 902 women with invasive breast cancer and 936 controls from the California Teachers Study investigated the association between serum levels of BDE- 
Table 1 Distribution of selected characteristics for 394 study participants, E3N cohort

\begin{tabular}{|c|c|c|c|}
\hline & All & Control & Case \\
\hline & $\mathrm{N}(\%)$ or Mean (STD) & N(\%) or Mean (STD) & $\mathrm{N}(\%)$ or Mean (STD) \\
\hline All participants & $394(100)$ & $197(100)$ & $197(100)$ \\
\hline \multicolumn{4}{|c|}{ Menopausal status and age at menopause at baseline } \\
\hline Pre-menopausal & $78(19.8)$ & 39 (19.8) & 39 (19.8) \\
\hline Post-menopausal & $316(80.2)$ & $158(80.2)$ & $158(80.2)$ \\
\hline \multicolumn{4}{|c|}{ Menopausal status and age at menopause at case's date of diagnosis } \\
\hline Pre-menopausal & $3(0.8)$ & $2(1.0)$ & $1(0.5)$ \\
\hline Post-menopausal & $192(48.7)$ & $99(50.3)$ & $93(47.2)$ \\
\hline Age (years) at baseline & $56.3(6.2)$ & $56.3(6.2)$ & $56.3(6.2)$ \\
\hline Age (years) at case's date of diagnosis & $68.4(6.2)$ & $68.4(6.2)$ & $68.4(6.2)$ \\
\hline \multicolumn{4}{|l|}{ BMI $\left(\mathrm{kg} / \mathrm{m}^{2}\right)$ at baseline } \\
\hline$<25$ & $279(70.8)$ & $136(69.0)$ & $136(69.0)$ \\
\hline$\geq 25$ & $115(29.2)$ & $61(31.0)$ & $61(31.0)$ \\
\hline \multicolumn{4}{|l|}{ BMI $\left(\mathrm{kg} / \mathrm{m}^{2}\right)$ at case's date of diagnosis } \\
\hline$<25$ & $261(66.2)$ & $127(64.5)$ & $134(68.0)$ \\
\hline$\geq 25$ & $133(33.8)$ & $70(35.5)$ & $63(32.0)$ \\
\hline Total plasma lipid content (ng/L) & $5.4(0.8)$ & $5.4(0.9)$ & $5.4(0.8)$ \\
\hline \multicolumn{4}{|l|}{ Smoking status at baseline } \\
\hline Never & $192(48.7)$ & $90(45.7)$ & $102(51.8)$ \\
\hline Ever & $202(51.3)$ & $107(54.3)$ & $95(48.2)$ \\
\hline \multicolumn{4}{|c|}{ Physical activity (metabolic equivalent tasks (MET)-hour/week) at baseline } \\
\hline$<35$ & $202(51.3)$ & $100(50.8)$ & $102(51.8)$ \\
\hline$\geq 35$ & $192(48.7)$ & $97(49.2)$ & $95(48.2)$ \\
\hline \multicolumn{4}{|l|}{ Education level at baseline } \\
\hline$<B A C$ & $39(9.9)$ & $22(11.2)$ & $17(8.6)$ \\
\hline$B A C$ to $B A C+2$ & $192(48.7)$ & $98(49.7)$ & $94(47.7)$ \\
\hline$\geq B A C+2$ & $163(41.4)$ & $77(39.1)$ & $86(43.7)$ \\
\hline \multicolumn{4}{|c|}{ Personal history of benign breast disease at baseline } \\
\hline No & $250(63.5)$ & $135(68.5)$ & $115(58.4)$ \\
\hline Yes & $144(36.5)$ & $62(31.5)$ & $82(41.6)$ \\
\hline \multicolumn{4}{|l|}{ Family history of breast cancer } \\
\hline None & $281(71.3)$ & $146(74.1)$ & $135(68.5)$ \\
\hline In first-degree relatives & $61(15.5)$ & $31(15.7)$ & $30(15.2)$ \\
\hline In extended relatives & $52(13.2)$ & $20(10.2)$ & $32(16.3)$ \\
\hline \multicolumn{4}{|l|}{ Parity and age at first full-term pregnancy (FFTP) } \\
\hline No children & $57(14.5)$ & $22(11.2)$ & $35(17.8)$ \\
\hline 1 or 2 children and $<30$ years old at FFTP & $194(49.2)$ & $97(49.2)$ & $97(49.2)$ \\
\hline$\geq 3$ children and $<30$ years old at FFTP & $108(27.4)$ & $62(31.5)$ & $46(23.4)$ \\
\hline$\geq 30$ years old at FFTP & $35(8.9)$ & $16(8.1)$ & $19(9.6)$ \\
\hline \multicolumn{4}{|l|}{ Total breastfeeding duration } \\
\hline Never & $152(38.6)$ & $79(40.1)$ & $73(37.1)$ \\
\hline$\leq 6$ months & $164(41.6)$ & $85(43.1)$ & $79(40.1)$ \\
\hline$>6$ months & $78(19.8)$ & $33(16.8)$ & $45(22.8)$ \\
\hline
\end{tabular}

Age at menarche 
Table 1 Distribution of selected characteristics for 394 study participants, E3N cohort (Continued)

\begin{tabular}{|c|c|c|c|}
\hline & All & Control & Case \\
\hline & $\mathrm{N}(\%)$ or Mean (STD) & N(\%) or Mean (STD) & $\mathrm{N}(\%)$ or Mean (STD) \\
\hline$<13$ years & $178(45.2)$ & $95(48.2)$ & $83(42.1)$ \\
\hline$\geq 13$ years & $216(54.8)$ & $102(51.8)$ & $114(57.9)$ \\
\hline Current use of & & & \\
\hline No & $234(59.7)$ & $119(60.7)$ & $115(58.7)$ \\
\hline Yes & $158(40.1)$ & $77(39.1)$ & $81(41.1)$ \\
\hline Use of oral cor & & & \\
\hline Never & $150(38.1)$ & $79(40.1)$ & $71(36.0)$ \\
\hline Ever & $244(61.9)$ & $118(59.9)$ & $126(64.0)$ \\
\hline Adherence sco & & & \\
\hline$<$ median & $197(50.0)$ & $89(45.2)$ & $108(54.8)$ \\
\hline$>$ median & $197(50.0)$ & $108(54.8)$ & $89(45.2)$ \\
\hline Adherence sco & & & \\
\hline$<$ median & $197(50.0)$ & $98(49.7)$ & $99(50.3)$ \\
\hline$>$ median & $197(50.0)$ & 99 (50.3) & 98 (49.7) \\
\hline
\end{tabular}

47, -100 , and -153 and the risk of breast cancer, suggesting no association [14].

A hospital-based study conducted among native Alaskan women, including invasive and in situ breast cancer as cases $(n=75)$ and women with diagnoses of benign breast conditions as controls $(n=95)$, failed to find any statistically significant association between serum levels of BDE-47 and breast cancer risk [15]. Two studies have investigated the associations between levels of PBDEs in breast adipose tissue and the risk of breast cancer. The first one, a Californian hospital-based study, which enrolled women with histologically-confirmed invasive breast cancer as cases $(n=78)$ and women with benign histological changes as controls $(n=56)$,

Table 2 Distribution of PBDE and PBB-153 levels (ng/L plasma and ng/gr lipids) in plasma samples collected among 394 study participants between 1994 and 1999, E3N cohort

\begin{tabular}{|c|c|c|c|c|c|c|c|}
\hline & \multicolumn{2}{|l|}{ Cases } & \multicolumn{2}{|l|}{ Controls } & \multicolumn{2}{|l|}{ All } & \multirow{2}{*}{$\begin{array}{l}{ }^{*} P \\
\text { value }\end{array}$} \\
\hline & mean $(\mathrm{sd})$ & median (min-max) & mean (sd) & median (min-max) & mean $(\mathrm{sd})$ & median (min-max) & \\
\hline PBDE sum (ng/L plasma) & $10.66(10.46)$ & $8.43(2.62-100.21)$ & $11.06(14.22)$ & 8.37 (3.04-165.65) & $10.86(12.47)$ & $8.4(2.62-165.65)$ & 0.67 \\
\hline PBDE sum (ng/gr lipids) & $1.96(1.73)$ & $1.59(0.42-17.38)$ & $2.07(2.75)$ & $1.55(0.57-31.02)$ & $2.01(2.29)$ & $1.56(0.42-31.02)$ & 0.74 \\
\hline BDE-28 (ng/L plasma) & $2.14(4.07)$ & $0.23(0.03-2.99)$ & $2.30(4.80)$ & $0.22(0.03-3.9)^{* *}$ & $2.20(4.44)$ & $0.22(0.03-3.9)$ & 0.49 \\
\hline BDE-28 (ng/gr lipids) & $0.39(0.79)$ & $0.04(0.01-0.71)$ & $0.42(0.79)$ & $0.04(0.01-0.73)$ & $0.41(0.79)$ & $0.04(0.01-0.73)$ & 0.38 \\
\hline BDE-47 (ng/L plasma) & $1.25(1.29)$ & $3.26(0.39-63.95)$ & $1.36(1.80)$ & $3.21(0.85-82.65)$ & $1.30(1.56)$ & $3.26(0.39-82.65)$ & 0.89 \\
\hline BDE-47 (ng/gr lipids) & $0.23(0.21)$ & $0.63(0.07-11.4)$ & $0.25(0.35)$ & $0.60(0.17-15.48)$ & $0.24(0.29)$ & $0.62(0.07-15.48)$ & 0.92 \\
\hline BDE-99 (ng/L plasma) & $3.15(1.49)$ & $0.73(0.12-14.46)$ & $3.13(1.55)$ & $0.74(0.16-47.02)$ & $3.14(1.52)$ & $0.74(0.12-47.02)$ & 0.35 \\
\hline BDE-99 (ng/gr lipids) & $0.58(0.25)$ & $0.14(0.02-2.54)$ & $0.59(0.31)$ & $0.60(0.17-15.48)$ & $0.58(0.28)$ & $0.13(0.02-8.81)$ & 0.27 \\
\hline BDE-100 (ng/L plasma) & $0.19(0.15)$ & $0.95(0.13-12.28)$ & $0.22(0.32)$ & $0.92(0.23-15.85)$ & $0.21(0.25)$ & $0.94(0.13-15.85)$ & 0.92 \\
\hline BDE-100 (ng/gr lipids) & $0.04(0.03)$ & $0.17(0.03-1.84)$ & $0.04(0.06)$ & $0.18(0.04-2.97)$ & $0.04(0.05)$ & $0.18(0.03-2.97)$ & 0.87 \\
\hline BDE-153 (ng/L plasma) & $0.33(0.40)$ & $2.84(1.06-9.93)$ & $0.33(0.41)$ & $2.84(1.35-12.47)$ & $0.33(0.41)$ & $2.84(1.06-12.47)$ & 0.85 \\
\hline BDE-153 (ng/gr lipids) & $0.06(0.08)$ & $0.53(0.22-1.76)$ & $0.06(0.08)$ & $0.53(0.22-2.34)$ & $0.06(0.08)$ & $0.53(0.22-2.34)$ & 0.71 \\
\hline BDE-154 (ng/L plasma) & $4.62(6.64)$ & $0.16(0.02-1.16)^{* *}$ & $4.76(7.52)$ & $0.15(0.02-3.76)^{* *}$ & $4.69(7.09)$ & $0.16(0.02-3.76)$ & 0.61 \\
\hline BDE-154 (ng/gr lipids) & $0.84(1.11)$ & $0.03(0-0.17)$ & $0.89(1.46)$ & $0.03(0-0.7)$ & $0.86(1.29)$ & $0.03(0-0.7)$ & 0.52 \\
\hline PBB-153 (ng/L plasma) & $1.12(1.59)$ & $1.59(0.62-57.06)$ & $1.27(3.62)$ & $1.66(0.68-66.7)$ & $1.20(2.80)$ & $1.64(0.62-66.7)$ & 0.76 \\
\hline PBB-153 (ng/gr lipids) & $0.21(0.27)$ & $0.30(0.12-11.12)$ & $0.24(0.69)$ & $0.31(0.11-10.94)$ & $0.22(0.53)$ & $0.31(0.11-11.12)$ & 0.62 \\
\hline
\end{tabular}

* Kruskal-Wallis test

** minimum value $=$ limit of detection 


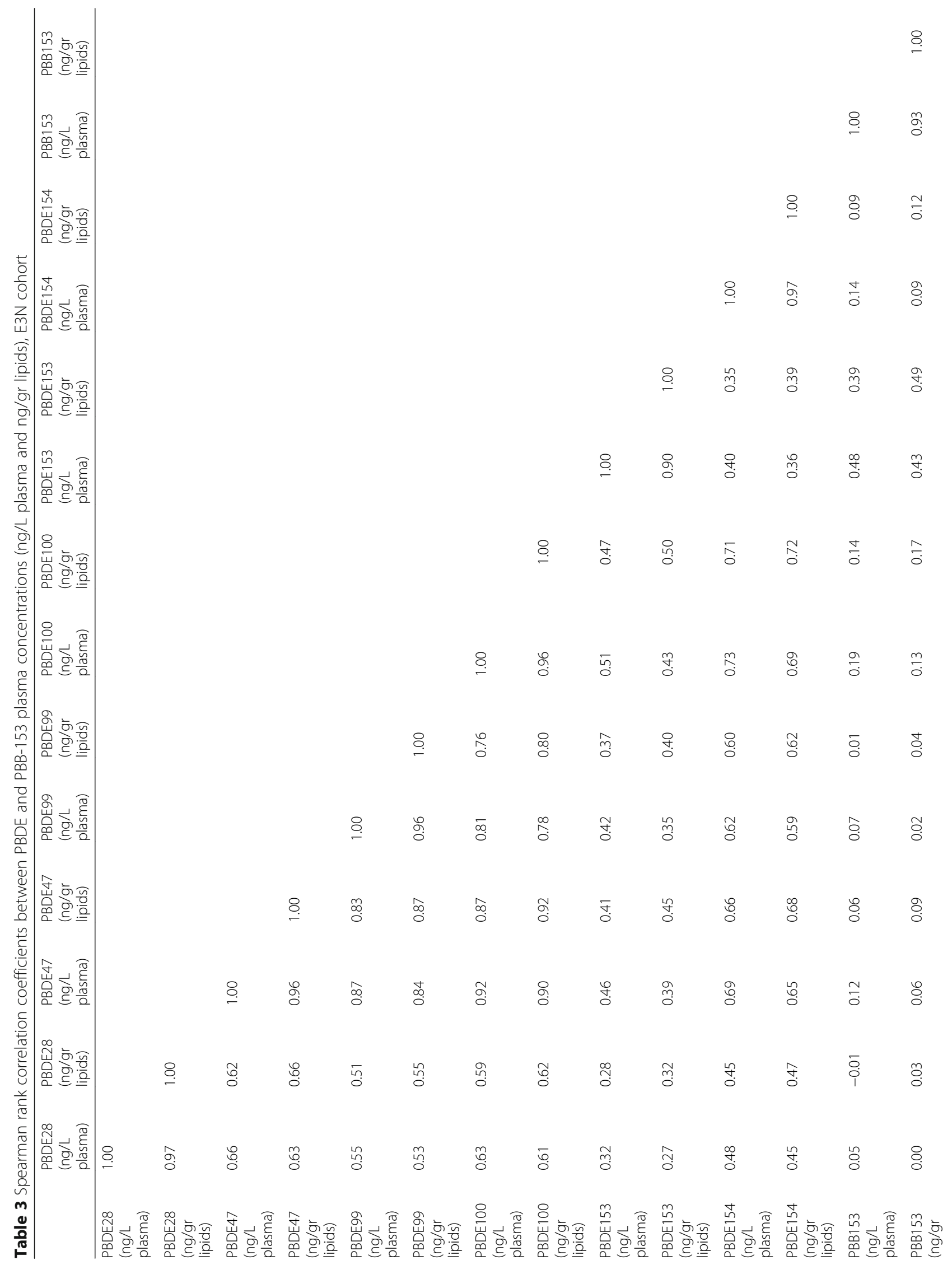




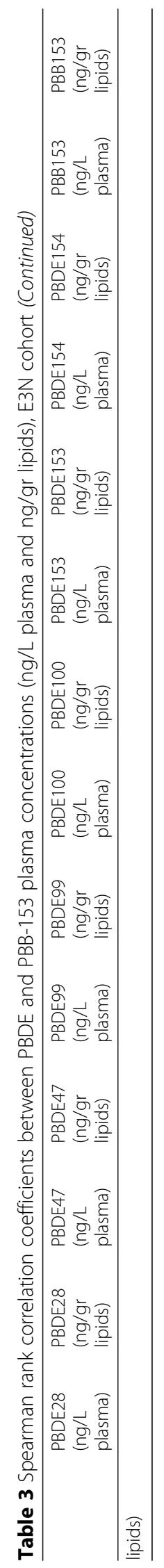


Table 4 Conditional logistic regression models to estimate the association between quintiles of PBDEs and PBB-153 plasma levels expressed in $\mathrm{ng} / \mathrm{L}$ and breast cancer risk: adjusted odds ratios (ORs) and 95\% confidence intervals (Cls) (E3N cohort, $N=394)$

\begin{tabular}{|c|c|c|c|c|c|c|c|c|}
\hline \multirow[t]{2}{*}{ ng/L plasma } & \multirow[b]{2}{*}{$\begin{array}{l}\text { Number (\%) } \\
\text { controls }\end{array}$} & \multirow[b]{2}{*}{ Number (\%) cases } & \multirow{2}{*}{$\begin{array}{l}\text { Model } 0 \\
\text { OR [95\% Cl] }\end{array}$} & \multirow{2}{*}{$\begin{array}{l}\mathrm{P} \\
\text { trend }\end{array}$} & \multirow{2}{*}{$\begin{array}{l}\text { Model } 1 \\
\text { OR [95\% Cl] }\end{array}$} & \multirow{2}{*}{$\begin{array}{l}\mathrm{P} \\
\text { trend }\end{array}$} & \multirow{2}{*}{$\begin{array}{l}\text { Model } 2 \\
\text { OR [95\% Cl] }\end{array}$} & \multirow{2}{*}{$\begin{array}{l}\mathrm{P} \\
\text { trend }\end{array}$} \\
\hline & & & & & & & & \\
\hline PBDE sum & 197 & 197 & & & & & & \\
\hline Q1 & $39(19.80)$ & $37(18.78)$ & Reference & 0.97 & Reference & 0.66 & Reference & 0.59 \\
\hline Q2 & $39(19.80)$ & $36(18.27)$ & $0.99[0.53 ; 1.84]$ & & $1.09[0.52 ; 2.26]$ & & $1.14[0.54 ; 2.41]$ & \\
\hline Q3 & 40(20.30) & $38(19.29)$ & $1.01[0.56 ; 1.82]$ & & $1.00[0.51 ; 1.94]$ & & $1.02[0.52 ; 2.00]$ & \\
\hline Q4 & $39(19.80)$ & $44(22.34)$ & $1.18[0.64 ; 2.18]$ & & $1.20[0.59 ; 2.44]$ & & $1.20[0.59 ; 2.46]$ & \\
\hline Q5 & 40(20.30) & $42(21.32)$ & $1.10[0.58 ; 2.08]$ & & $1.13[0.54 ; 2.39]$ & & $1.21[0.57 ; 2.58]$ & \\
\hline log-PBDE sum & & & $0.98[0.67 ; 1.42]$ & 0.9 & $0.95[0.62 ; 1.46]$ & 0.83 & $0.97[0.63 ; 1.50]$ & 0.88 \\
\hline $\mathrm{BDE}-28$ & 197 & 197 & & & & & & \\
\hline Q1 & $39(19.80)$ & $34(17.26)$ & Reference & 0.32 & Reference & 0.47 & Reference & 0.54 \\
\hline Q2 & 39(19.80) & $40(20.30)$ & $1.16[0.62-2.18]$ & & 1.39 [0.67-2.90] & & $1.36[0.65-2.85]$ & \\
\hline Q3 & $40(20.30)$ & $34(17.26)$ & $0.99[0.51-1.91]$ & & $0.92[0.43-1.97]$ & & $0.99[0.46-2.14]$ & \\
\hline Q4 & $39(19.80)$ & $41(20.81)$ & $1.18[0.62-2.26]$ & & $1.29[0.61-2.72]$ & & 1.32 [0.63-2.80] & \\
\hline Q5 & $40(20.30)$ & $48(24.37)$ & $1.36[0.72-2.53]$ & & $1.33[0.65-2.70]$ & & $1.27[0.62-2.60]$ & \\
\hline $\log -B D E-28$ & & & $1.04[0.80 ; 1.37]$ & 0.75 & $1.00[0.74 ; 1.35]$ & 0.98 & $0.97[0.72 ; 1.33]$ & 0.87 \\
\hline $\mathrm{BDE}-47$ & 197 & 197 & & & & & & \\
\hline Q1 & $39(19.80)$ & $41(20.81)$ & Reference & 0.72 & Reference & 0.81 & Reference & 0.72 \\
\hline Q2 & $39(19.80)$ & $34(17.26)$ & $0.82[0.43-1.56]$ & & $0.71[0.35-1.47]$ & & $0.73[0.35-1.53]$ & \\
\hline Q3 & 40(20.30) & 38 (19.29) & $0.91[0.50-1.67]$ & & 0.98 [0.49-1.95] & & $1.01[0.50-2.05]$ & \\
\hline Q4 & $39(19.80)$ & $40(20.30)$ & $0.97[0.53-1.79]$ & & $0.84[0.42-1.67]$ & & $0.83[0.41-1.69]$ & \\
\hline Q5 & $40(20.30)$ & $44(22.34)$ & $1.06[0.57-1.95]$ & & $1.05[0.52-2.11]$ & & $1.11[0.54-2.26]$ & \\
\hline log-BDE-47 & & & $0.94[0.70 ; 1.25]$ & 0.66 & $0.92[0.66 ; 1.29]$ & 0.64 & $0.94[0.67 ; 1.32]$ & 0.72 \\
\hline BDE-99 & 197 & 197 & & & & & & \\
\hline Q1 & 39(19.80) & 31 (15.74) & Reference & 0.55 & Reference & 0.66 & Reference & 0.66 \\
\hline Q2 & 39(19.80) & $45(22.84)$ & $1.50[0.77-2.90]$ & & $1.30[0.62-2.73]$ & & $1.23[0.57-2.62]$ & \\
\hline Q3 & $40(20.30)$ & 38 (19.29) & $1.27[0.64-2.50]$ & & $1.26[0.59-2.71]$ & & 1.32 [0.60-2.90] & \\
\hline Q4 & 39(19.80) & $41(20.81)$ & $1.38[0.70-2.72]$ & & $1.20[0.56-2.56]$ & & $1.09[0.50-2.38]$ & \\
\hline Q5 & 40(20.30) & $42(21.32)$ & $1.36[0.69-2.66]$ & & $1.28[0.59-2.75]$ & & 1.29 [0.59-2.83] & \\
\hline log-BDE-99 & & & $1.04[0.78 ; 1.39]$ & 0.79 & $1.06[0.76 ; 1.48]$ & 0.72 & $1.07[0.77 ; 1.49]$ & 0.69 \\
\hline BDE-100 & 197 & 197 & & & & & & \\
\hline Q1 & $39(19.80)$ & $49(24.87)$ & Reference & 0.53 & Reference & 0.41 & Reference & 0.46 \\
\hline Q2 & $39(19.80)$ & $36(18.27)$ & $0.71[0.38-1.33]$ & & $0.56[0.27-1.17]$ & & $0.59[0.28-1.27]$ & \\
\hline Q3 & $40(20.30)$ & $29(14.72)$ & $0.54[0.28-1.05]$ & & $0.42[0.19-0.92]$ & & $0.42[0.19-0.93]$ & \\
\hline Q4 & $39(19.80)$ & $46(23.35)$ & $0.93[0.51-1.70]$ & & $0.91[0.46-1.80]$ & & $0.87[0.44-1.74]$ & \\
\hline Q5 & $40(20.30)$ & 37 (18.78) & $0.68[0.35-1.30]$ & & $0.53[0.24-1.17]$ & & $0.58[0.26-1.28]$ & \\
\hline Log-BDE100 & & & $0.89[0.65 ; 1.20]$ & 0.44 & $0.95[0.53 ; 1.70]$ & 0.85 & $0.97[0.54 ; 1.75]$ & 0.91 \\
\hline BDE-153 & 197 & 197 & & & & & & \\
\hline Q1 & $39(19.80)$ & $43(21.83)$ & Reference & 0.92 & Reference & 0.73 & Reference & 0.78 \\
\hline Q2 & 39(19.80) & $45(22.84)$ & $1.08[0.58-2.01]$ & & $1.30[0.63-2.68]$ & & $1.28[0.62-2.67]$ & \\
\hline Q3 & $40(20.30)$ & $22(11.17)$ & $0.52[0.26-1.01]$ & & $0.40[0.17-0.90]$ & & $0.42[0.18-0.98]$ & \\
\hline Q4 & $39(19.80)$ & $44(22.34)$ & $1.02[0.56-1.87]$ & & 1.10 [0.55-2.22] & & $1.12[0.55-2.29]$ & \\
\hline Q5 & $40(20.30)$ & $43(21.83)$ & $0.96[0.52-1.76]$ & & $0.85[0.42-1.74]$ & & $0.87[0.43-1.79]$ & \\
\hline log-BDE-153 & & & $1.02[0.62 ; 1.68]$ & 0.94 & $0.95[0.53 ; 1.70]$ & 0.85 & $0.97[0.54 ; 1.75]$ & 0.91 \\
\hline
\end{tabular}


Table 4 Conditional logistic regression models to estimate the association between quintiles of PBDEs and PBB-153 plasma levels expressed in $\mathrm{ng} / \mathrm{L}$ and breast cancer risk: adjusted odds ratios (ORs) and 95\% confidence intervals (Cls) (E3N cohort, N = 394) (Continued)

\begin{tabular}{|c|c|c|c|c|c|c|c|c|}
\hline \multirow[t]{2}{*}{ ng/L plasma } & \multirow[b]{2}{*}{$\begin{array}{l}\text { Number (\%) } \\
\text { controls }\end{array}$} & \multirow[b]{2}{*}{ Number (\%) cases } & \multirow{2}{*}{$\begin{array}{l}\text { Model } 0 \\
\text { OR [95\% CI] }\end{array}$} & \multirow{2}{*}{$\begin{array}{l}P \\
\text { trend }\end{array}$} & \multirow{2}{*}{$\begin{array}{l}\text { Model } 1 \\
\text { OR [95\% Cl] }\end{array}$} & \multirow{2}{*}{$\begin{array}{l}\mathrm{P} \\
\text { trend }\end{array}$} & \multirow{2}{*}{$\begin{array}{l}\text { Model } 2 \\
\text { OR [95\% Cl] }\end{array}$} & \multirow{2}{*}{$\begin{array}{l}\mathrm{P} \\
\text { trend }\end{array}$} \\
\hline & & & & & & & & \\
\hline BDE-154 & 197 & 197 & & & & & & \\
\hline Q1 & $39(19.80)$ & 35 (17.77) & Reference & 0.47 & Reference & 0.86 & Reference & 0.86 \\
\hline Q2 & $39(19.80)$ & 38 (19.29) & $1.09[0.56-2.11]$ & & $0.93[0.44-1.97]$ & & $0.91[0.43-1.96]$ & \\
\hline Q3 & $40(20.30)$ & 38 (19.29) & $1.08[0.57-2.07]$ & & $1.04[0.50-2.15]$ & & $1.06[0.51-2.21]$ & \\
\hline Q4 & $39(19.80)$ & $43(21.83)$ & $1.26[0.66-2.43]$ & & $1.14[0.54-2.41]$ & & $1.13[0.53-2.40]$ & \\
\hline Q5 & $40(20.30)$ & $43(21.83)$ & $1.24[0.64-2.40]$ & & $1.00[0.47-2.13]$ & & $1.00[0.46-2.15]$ & \\
\hline log-BDE-154 & & & $0.99[0.75 ; 1.31]$ & 0.95 & $0.97[0.70 ; 1.33]$ & 0.83 & $0.96[0.70 ; 1.33]$ & 0.82 \\
\hline PBB-153 & 197 & 197 & & & & & & \\
\hline Q1 & $39(19.80)$ & $47(23.86)$ & Reference & 0.31 & Reference & 0.33 & Reference & 0.29 \\
\hline Q2 & $39(19.80)$ & $41(20.81)$ & 0.90 [0.50-1.61] & & $0.73[0.38-1.41]$ & & $0.67[0.34-1.31]$ & \\
\hline Q3 & $40(20.30)$ & 29 (14.72) & $0.58[0.31-1.11]$ & & $0.49[0.23-1.07]$ & & $0.48[0.22-1.06]$ & \\
\hline Q4 & 39(19.80) & $51(25.89)$ & $1.06[0.57-1.97]$ & & $0.96[0.47-1.96]$ & & $0.92[0.45-1.90]$ & \\
\hline Q5 & $40(20.30)$ & $29(14.72)$ & 0.58 [0.29-1.13] & & $0.53[0.24-1.17]$ & & $0.50[0.22-1.13]$ & \\
\hline log-PBB-153 & & & $1.02[0.62 ; 1.68]$ & 0.94 & $0.95[0.53 ; 1.70]$ & 0.85 & $0.97[0.54 ; 1.75]$ & 0.91 \\
\hline
\end{tabular}

Model 0: crude estimates;

Model 1: adjusted for total plasma lipid content (ng/L, continuous), smoking status (never vs. ever), physical activity measured in metabolic equivalent tasks (MET)hour/week ( $<35$ vs. $\geq 35$ ), education ( $\leq 12$ years, 12 to 14 years, $>14$ years), personal history of benign breast disease (no vs. yes), and family history of breast cancer (none, in first-degree relatives, in extended relatives), parity and age at first full-term pregnancy (FFTP) (no children, 1 or 2 children and $<30$ years old at FFTP, $\geq 3$ children and $<30$ years old at FFTP, $\geq 30$ years old at FFTP), total breastfeeding duration (never, $\leq 6$ or $>6$ months), age at menarche ( $<13$ years vs. $\geq 13$ years), current use of menopausal hormone therapy (pre-menopausal, yes, no), and use of oral contraceptives (ever vs. never), menopausal status and age at menopause (pre-menopausal, menopause before age 51, menopause at age 51 or later);

Model 2: Model $1+$ adherence score to the Healthy and the Western dietary patterns (above vs. below the median)

provided no evidence of an association between adipose tissue concentrations of BDE-47, $-99,-100,-153$, and -154 and breast cancer risk [16]. The second was a hospital-based study conducted in China (Shantou, Chaoshan area) and included 209 cases and 165 controls. In multivariable models adjusted for age and menarcheal age, adipose tissue levels of BDE-47, - 71, - 99, $-100,-183$ and -209 were independently and positively associated with breast-cancer risk [17]. Some major differences need to be considered when comparing these previous findings with our results. First, these studies had a retrospective case-control design, implying that the exposure level was measured at the time of diagnosis (or after diagnosis), while in the present study blood samples were drawn before breast cancer diagnosis. Moreover, in the latter two studies, PBDE levels were measured in adipose tissue, while in our study only levels measured in blood were available.

Of note, a nested case-control study was conducted based on 51 cases of breast cancer and 202 controls selected among women residents in Michigan during the industrial accident in 1973, which led to a high contamination of the local food chain with PBB [18]. This study found an OR of 2.60 (95\% CI 0.93-7.27) for breast cancer incidence in women with a serum level of $\mathrm{PBB} \geq 10$ $\mathrm{ng} / \mathrm{mL}$ compared with women with $\mathrm{PBB} \leq 1 \mathrm{ng} / \mathrm{mL}$. Although not statistically significant, these results confirmed those found in two previous studies in the same population that were performed within a shorter time interval after the accident. Henderson et al. (follow-up through 1992) and Hoque et al. (follow-up through 1993) found non-statistically significant positive associations between PBB exposure and breast cancer risk [19, 20]. These studies differed from ours in the fact that the Michigan population represents a highly exposed group, with circulating levels 1000-fold higher compared with those found in our study population.

The exposure levels of PBDEs in our study were substantially lower compared to other previous studies with a similar blood collection time. These diverging biomonitoring profiles are aligned with the higher production of BFRs in US (e.g. 3-7 folds) in comparison to Europe between late $70 \mathrm{~s}$ and $90 \mathrm{~s}$ [6]. For instance, the median concentration of BDE-153 was $6.5-7.2 \mathrm{ng} / \mathrm{g}$ in adipose tissue from US [16] and $0.53 \mathrm{ng}$ BDE-153/g lipid of plasma from France in the 90s (present study). These lower levels of exposure in France are further supported by subsequent studies conducted in US, finding a median of $4.8 \mathrm{ng} / \mathrm{g}$ lipid of serum between 2003 and 2004 [32], or in China, showing a range between 26.02-31.02 
Table 5 Conditional logistic regression models to estimate the association between quintiles of PBDE and PBB-153 plasma levels expressed as ng/gr of lipids and breast cancer risk: adjusted odds ratios (ORs) and 95\% confidence intervals (Cls) $(N=394)$

\begin{tabular}{|c|c|c|c|c|c|c|c|c|}
\hline ng/gr lipids in the plasma & $\begin{array}{l}\text { Number (\%) } \\
\text { controls }\end{array}$ & Number(\%) cases & $\begin{array}{l}\text { Model } 0 \\
\text { OR [95\% Cl] }\end{array}$ & $P$ trend & $\begin{array}{l}\text { Model } 1 \\
\text { OR [95\% CI] }\end{array}$ & $P$ trend & $\begin{array}{l}\text { Model } 2 \\
\text { OR [95\% Cl] }\end{array}$ & $P$ trend \\
\hline PBDE sum & 197 & 197 & & & & & & \\
\hline Q1 & $39(19.80)$ & $44(22.34)$ & Reference & 0,85 & Reference & 0.82 & Reference & 0.74 \\
\hline Q2 & $39(19.80)$ & $29(14.72)$ & $0.68[0.36-1.27]$ & & $0.56[0.27-1.14]$ & & $0.63[0.30-1.30]$ & \\
\hline Q3 & $40(20.30)$ & 39(19.80) & $0.90[0.51-1.59]$ & & $0.92[0.49-1.71]$ & & $0.90[0.48-1.70]$ & \\
\hline Q4 & $39(19.80)$ & $36(18.27)$ & $0.82[0.45-1.50]$ & & $0.77[0.38-1.53]$ & & $0.85[0.42-1.72]$ & \\
\hline Q5 & $40(20.30)$ & $49(24.87)$ & $1.10[0.60-2.01]$ & & $0.96[0.48-1.91]$ & & $1.01[0.50-2.01]$ & \\
\hline log-PBDE sum & 197 & 197 & $0.99[0.68-1.45]$ & 0.98 & $0.95[0.62-1.46]$ & 0.81 & $0.96[0.62-1.49]$ & 0.86 \\
\hline \multicolumn{9}{|l|}{$\mathrm{BDE}-28$} \\
\hline Q1 & $39(19.80)$ & $35(17.77)$ & Reference & 0.36 & Reference & & Reference & 0.64 \\
\hline Q2 & $39(19.80)$ & $39(19.80)$ & $1.09[0.58-2.02]$ & & $1.56[0.76-3.20]$ & 0.55 & $1.48[0.71-3.09]$ & \\
\hline Q3 & $40(20.30)$ & $33(16.75)$ & $0.91[0.48-1.74]$ & & $0.87[0.41-1.86]$ & & $0.91[0.42-1.96]$ & \\
\hline Q4 & 39(19.80) & $43(21.83)$ & $1.19[0.65-2.17]$ & & $1.22[0.61-2.45]$ & & $1.34[0.67-2.71]$ & \\
\hline Q5 & $40(20.30)$ & $47(23.86)$ & $1.27[0.70-2.30]$ & & $1.28[0.65-2.50]$ & & $1.19[0.60-2.36]$ & \\
\hline log-BDE-28 & & & $1.05[0.81-1.38]$ & 0.7 & $0.99[0.74-1.34]$ & 0.9728 & $0.97[0.71-1.33]$ & 0.85 \\
\hline $\mathrm{BDE}-47$ & 197 & 197 & & & & & & \\
\hline Q1 & $39(19.80)$ & $41(20.81)$ & Reference & 0.95 & Reference & 0.89 & Reference & 1,00 \\
\hline Q2 & $39(19.80)$ & $36(18.27)$ & 0.89 [0.49-1.61] & & 0.76 [0.39-1.47] & & $0.73[0.37-1.44]$ & \\
\hline Q3 & $40(20.30)$ & $37(18.78)$ & 0.89 [0.49-1.62] & & 0.79 [0.40-1.53] & & $0.74[0.37-1.46]$ & \\
\hline Q4 & 39(19.80) & $43(21.83)$ & 1.04 [0.59-1.86] & & 0.97 [0.50-1.88] & & 0.98 [0.50-1.93] & \\
\hline Q5 & $40(20.30)$ & $40(20.30)$ & $0.95[0.51-1.79]$ & & $0.89[0.44-1.80]$ & & $0.93[0.45-1.92]$ & \\
\hline log-BDE-47 & & & $0.95[0.71-1.27]$ & 0.71 & $0.92[0.66-1.29]$ & 0.6317 & $0.94[0.66-1.32]$ & 0.70 \\
\hline BDE-99 & 197 & 197 & & & & & & \\
\hline Q1 & $39(19.80)$ & $32(16.24)$ & Reference & 0.44 & Reference & 0.57 & Reference & 0.55 \\
\hline Q2 & $39(19.80)$ & 38(19.29) & $1.23[0.63-2.41]$ & & $1.20[0.58-2.49]$ & & $1.25[0.59-2.64]$ & \\
\hline Q3 & $40(20.30)$ & $40(20.30)$ & $1.25[0.64-2.44]$ & & $1.27[0.61-2.64]$ & & $1.34[0.64-2.84]$ & \\
\hline Q4 & $39(19.80)$ & $46(23.35)$ & $1.47[0.76-2.83]$ & & $1.24[0.60-2.58]$ & & $1.20[0.57-2.52]$ & \\
\hline Q5 & $40(20.30)$ & $41(20.81)$ & $1.27[0.66-2.44]$ & & $1.27[0.61-2.67]$ & & $1.33[0.63-2.81]$ & \\
\hline log-BDE-99 & & & $1.05[0.79-1.41]$ & 0.73 & $1.06[0.76-1.47]$ & 0.73 & 1.07 [0.76-1.49] & 0.70 \\
\hline BDE-100 & 197 & 197 & & & & & & \\
\hline Q1 & $39(19.80)$ & $43(21.83)$ & Reference & 0.99 & Reference & 0.88 & Reference & 0.97 \\
\hline Q2 & 39(19.80) & $41(20.81)$ & 0.97 [0.53-1.81] & & $0.85[0.42-1.69]$ & & $0.99[0.48-2.01]$ & \\
\hline Q3 & $40(20.30)$ & $29(14.72)$ & $0.66[0.35-1.27]$ & & $0.58[0.27-1.24]$ & & $0.58[0.27-1.25]$ & \\
\hline Q4 & 39(19.80) & $40(20.30)$ & $0.94[0.52-1.72]$ & & $0.96[0.48-1.91]$ & & 0.96 [0.48-1.93] & \\
\hline Q5 & $40(20.30)$ & $44(22.34)$ & $1.01[0.52-1.94]$ & & $0.87[0.41-1.84]$ & & $0.99[0.46-2.13]$ & \\
\hline log-BDE-100 & & & $0.90[0.66-1.22]$ & 0.48 & $0.86[0.60-1.22]$ & 0.40 & $0.87[0.61-1.25]$ & 0.46 \\
\hline BDE-153 & 197 & 197 & & & & & & \\
\hline Q1 & $39(19.80)$ & $48(24.37)$ & Reference & 0.85 & Reference & 0.84 & Reference & 0.87 \\
\hline Q2 & $39(19.80)$ & $34(17.26)$ & 0.68 [0.36-1.30] & & $0.60[0.28-1.27]$ & & $0.62[0.29-1.31]$ & \\
\hline Q3 & $40(20.30)$ & $29(14.72)$ & 0.57 [0.30-1.09] & & $0.52[0.24-1.12]$ & & $0.53[0.25-1.17]$ & \\
\hline Q4 & $39(19.80)$ & $36(18.27)$ & $0.69[0.35-1.34]$ & & $0.75[0.34-1.63]$ & & $0.83[0.37-1.85]$ & \\
\hline Q5 & $40(20.30)$ & $50(25.38)$ & $1.00[0.56-1.80]$ & & $0.81[0.41-1.61]$ & & $0.80[0.40-1.61]$ & \\
\hline log-BDE-153 & & & $1.06[0.64-1.76]$ & 0.83 & 0.94 [0.52-1.68] & 0.82 & $0.96[0.53-1.73]$ & 0.88 \\
\hline BDE-154 & 197 & 197 & & & & & & \\
\hline
\end{tabular}


Table 5 Conditional logistic regression models to estimate the association between quintiles of PBDE and PBB-153 plasma levels expressed as ng/gr of lipids and breast cancer risk: adjusted odds ratios (ORs) and 95\% confidence intervals (Cls) $(N=394)$ (Continued)

\begin{tabular}{|c|c|c|c|c|c|c|c|c|}
\hline ng/gr lipids in the plasma & $\begin{array}{l}\text { Number (\%) } \\
\text { controls }\end{array}$ & Number(\%) cases & $\begin{array}{l}\text { Model } 0 \\
\text { OR [95\% Cl] }\end{array}$ & $P$ trend & $\begin{array}{l}\text { Model } 1 \\
\text { OR [95\% Cl] }\end{array}$ & $P$ trend & $\begin{array}{l}\text { Model } 2 \\
\text { OR [95\% Cl] }\end{array}$ & $P$ trend \\
\hline Q1 & $39(19.80)$ & $33(16.75)$ & Reference & 0.45 & Reference & 0.75 & Reference & 0.76 \\
\hline Q2 & $39(19.80)$ & 38(19.29) & $1.18[0.61-2.28]$ & & $0.91[0.43-1.92]$ & & $0.86[0.40-1.85]$ & \\
\hline Q3 & $40(20.30)$ & $41(20.81)$ & $1.26[0.63-2.51]$ & & $1.30[0.61-2.78]$ & & $1.35[0.63-2.90]$ & \\
\hline Q4 & $39(19.80)$ & $46(23.35)$ & $1.48[0.74-2.97]$ & & 1.37 [0.63-2.98] & & $1.26[0.58-2.77]$ & \\
\hline Q5 & $40(20.30)$ & $39(19.80)$ & $1.24[0.63-2.44]$ & & $0.99[0.46-2.11]$ & & $0.97[0.45-2.10]$ & \\
\hline log-BDE-154 & & & $0.99[0.75-1.32]$ & 0.97 & $0.95[0.69-1.31]$ & 0.77 & $0.95[0.69-1.32]$ & 0.77 \\
\hline PBB-153 & 197 & 197 & & & & & & \\
\hline Q1 & $39(19.80)$ & $37(18.78)$ & Reference & 0.59 & Reference & 0.80 & Reference & 0.74 \\
\hline Q2 & $39(19.80)$ & $44(22.34)$ & $1.21[0.63-2.32]$ & & $1.25[0.60-2.61]$ & & $1.19[0.56-2.56]$ & \\
\hline Q3 & $40(20.30)$ & $41(20.81)$ & $1.12[0.58-2.15]$ & & $1.09[0.52-2.30]$ & & $1.05[0.49-2.27]$ & \\
\hline Q4 & $39(19.80)$ & $53(26.90)$ & $1.41[0.73-2.72]$ & & $1.74[0.81-3.75]$ & & $1.83[0.83-4.04]$ & \\
\hline Q5 & $40(20.30)$ & $22(11.17)$ & $0.62[0.30-1.28]$ & & $0.61[0.27-1.38]$ & & $0.52[0.22-1.23]$ & \\
\hline log-PBB-153 & & & $1.06[0.64-1.76]$ & 0.83 & $0.94[0.52-1.68]$ & 0.83 & 0.96 [0.53-1.73] & 0.88 \\
\hline
\end{tabular}

Model 0: crude estimates;

Model 1: adjusted for smoking status (never vs. ever), physical activity measured in metabolic equivalent tasks (MET)-hour/week $(<35$ vs. $\geq 35)$, education $(\leq 12$ years, 12 to 14 years, $>14$ years), personal history of benign breast disease (no vs. yes), and family history of breast cancer (none, in first-degree relatives, in extended relatives), parity and age at first full-term pregnancy (FFTP) (no children, 1 or 2 children and $<30$ years old at FFTP, $\geq 3$ children and $<30$ years old at FFTP, $\geq 30$ years old at FFTP), total breastfeeding duration (never, $\leq 6$ or $>6$ months), age at menarche ( $<13$ years vs. $\geq 13$ years), current use of menopausal hormone therapy (pre-menopausal, yes, no), and use of oral contraceptives (ever vs. never), menopausal status and age at menopause (pre-menopausal, menopause before age 51, menopause at age 51 or later);

Model 2: Model $1+$ adherence score to the Healthy and the Western dietary patterns (above vs. below the median)

ng/g in adipose tissue between 2014 and 2016 [17], whereas in France a median of $0.75 \mathrm{ng} / \mathrm{g}$ lipid of serum has been reported in the last biomonitoring study (2014-2016) [33]. Moreover, our improved analytical method substantially increased the sensitivity and the number of detected samples, for instance, our mean LOD for BDE153 was $0.1 \mathrm{ng} / \mathrm{L}$ whereas previous studies have reported LOD of $17 \mathrm{ng} / \mathrm{L}$ [16].

Overall, we interpret the results from our study as null findings. However, it should be noted that when running the analyses with the exposure expressed as $\mathrm{ng} / \mathrm{L}$ of plasma, we observed a non-linear inverse association between levels of PBDE-100 and -153 and breast cancer risk; nevertheless, this association was not statistically significant when considering concentrations in ng/gr of lipids in the plasma. With few exceptions, stratification by tumor hormone receptor expression and BMI categories yielded similar results as the main analyses. Therefore, given the relatively small number of cases upon which these estimates are based, the inconsistency in the results obtained for other PBDEs included in the study, and the numerous statistical analyses that were conducted, it is probable that these findings are due to chance.

When interpreting these results, a limitation of our study that should be taken into consideration is that only a single measurement of PBDE and PBB-153 concentrations was available; we thus had no information on the true trajectories of exposure or on exposure levels during sensitive periods of breast development. The present study was conducted with a population exposed to low background levels of PBDEs and PBBs limiting the conclusion to the low end of the population dose-response curve. Moreover, previous studies have suggested that certain genetic factors may modify the associations between exposure to EDCs and risk of breast cancer [34], but no genetic information was available in our study to investigate this hypothesis. Additionally, PBDE and PBB-153 levels were measured in blood plasma and no information on breast adipose tissue levels of PBDEs and PBB-153 were available. Despite the fact that blood biomarkers of lipophilic pollutants are acknowledged to be good predictors of levels in adipose tissue, many factors may affect the partition between lipids from both compartments. For instance, the average partition adipose tissue:serum of PBDEs in lipid basis was estimated around 0.5 for the congeners BDE28, -47 and -99 and between 0.8 and 1.1 for BDE-153, -154 and -183 in Chinese women [35]. This imperfect partition may hamper the interpretation of risk models when using circulating biomarkers as proxies of adipose tissue estimates, resulting, in some cases, in associations in opposite directions [36]. Nonetheless, the systematic comparison between models with lipid-adjusted and 
wet-basis biomarkers did not yield substantial modifications of risk estimates, thus ruling out more complex underlying associations. We used the parent forms of PBDEs as biomarkers of internal exposure, while little is known about the potential adverse health effects of their hydroxylated forms as products of biotransformation metabolism, which have shown exert estrogenic effects [37]. Thus, one hypothesis to be deeper investigated for explaining the observed reverse associations would be the potential protective effect of adipose tissue by sequestrating the parent compounds and more biologically active hydroxylated metabolites, preventing the release into circulation and thus the exposure of carcinogenic cells [38]. Finally, we would also emphasize that, despite the fact that the biomarkers were mostly detected in all samples, we were not able to detect BDE-154 in $25 \%$ of samples; thus, the related results should be considered with caution due to the risk of bias associated to the substitution of non-detected samples by $1 / 2$ LOD.

Nevertheless, our study presents several strengths. Thanks to the long follow-up duration of the E3N cohort, we were able to prospectively investigate the long-term health effects of plasma concentrations of PBDEs and PBB153. Extensive information on the main breast cancer risk factors, such as reproductive history, use of hormonal treatments, anthropometric characteristics, and lifestyle-related risk factors, was collected prospectively in the cohort and thus at the same time for cases and controls. Finally, the availability of information on breast cancer expression of estrogen and progesterone receptors allowed us to better characterize the tumors and to perform stratified analyses.

\section{Conclusion}

Our results suggest no clear association between internal levels of PBDEs and PBB-153 and risk of breast cancer in postmenopausal women. Although our results are similar to those found in previous research, they need to be carefully interpreted, taking into account study limitations due to the limited number of women included in the study, the lack of information concerning genetic susceptibility, and the unavailability of exposure assessment during critical windows of susceptibility for breast cancer. More studies are warranted to further investigate the relationships between PBDE and PBB exposure and breast cancer risk, in particular through deeper investigation related to the link between those markers and lipids, and documenting exposure levels for potentially active PBDE metabolites.

\section{Supplementary information}

Supplementary information accompanies this paper at https://doi.org/10. 1186/s12940-020-00607-9.

Additional file 1 Table S1. Multinomial regression models to estimate the association between quintiles of PBDEs and PBB-153 plasma level expressed as ng/L and breast cancer risk stratified according to hormone estrogen receptor status: adjusted odds ratios (ORs) and 95\% confidence intervals (Cls). Table S2. Multinomial regression models to estimate the association between quintiles of PBDEs and PBB-153 plasma level expressed as $n g / L$ and breast cancer risk stratified according to hormone progesteron receptor status: adjusted odds ratios (ORs) and $95 \%$ confidence intervals (Cls). Table S3. Multinomial regression models to estimate the association between quintiles of PBDEs and PBB-153 plasma level expressed as ng/gr of lipids and breast cancer risk stratified according to hormone estrogen receptor status: adjusted odds ratios (ORs) and 95\% confidence intervals ( $\mathrm{Cls}$ ). Table $\mathbf{S 4}$. Multinomial regression models to estimate the association between quintiles of PBDEs and PBB-153 plasma level expressed as ng/gr of lipids and breast cancer risk stratified according to hormone progesteron receptor status: adjusted odds ratios (ORs) and 95\% confidence intervals (Cls). Table S5. Conditional logistic regression models to estimate the association between quintiles of PBDEs and PBB-153 plasma levels expressed as ng/L and breast cancer risk stratified according to the body mass index (BMI): adjusted odds ratios (ORs) and 95\% confidence intervals (Cls) Table S6. Conditional logistic regression models to estimate the association between quintiles of PBDEs and PBB-153 plasma levels expressed as ng/gr of lipids and breast cancer risk stratified according to the body mass index (BMI): adjusted odds ratios (ORs) and 95\% confidence intervals (Cls)

\section{Acknowledgments}

The authors would like to acknowledge all women enrolled in the E3N cohort for their continued participation. They are also grateful to all members of the $\mathrm{E} 3 \mathrm{~N}$ study group.

\section{Availability of supporting data}

The datasets used and/or analysed during the current study are available from the corresponding author on reasonable request.

\section{Authors' contributions}

FRM and OM analyzed all data. GCS, PM, and JPA isolated, detected, and quantified the PBDEs and PBB congeners. All authors contributed in the interpretation of the results. FRM was the major contributor in writing the article. All authors read and approved the final manuscript.

\section{Authors' information}

\section{Not applicable}

\section{Funding}

This work was realized with the data of the E3N cohort of the Inserm and supported by the Mutuelle Générale de l'Education Nationale (MGEN), the Gustave Roussy Institute, and the French League against Cancer for the constitution and maintenance of the cohort. The work was also supported by the grant EQ. 9-C17014LS from the Cancer ITMO of the French National Alliance for Life and Health Sciences (AVIESAN), in collaboration with the Institut National du Cancer (French National Cancer Institute) and Inserm.

\section{Ethics approval and consent to participate}

The study was approved by the French National Commission for Data Protection and Privacy. All participants signed an informed consent at recruitment.

\section{Consent for publication}

Not applicable.

\section{Competing interests}

The authors declare they have no actual or potential competing financial interests.

\section{Author details}

'CESP, Faculté de médecine, Université Paris-Saclay, UVSQ, INSERM, Villejuif, France. ${ }^{2}$ Gustave Roussy, Villejuif, France. ${ }^{3}$ LABERCA, Oniris, INRAE, Nantes, France. ${ }^{4}$ Breast and Gynaecologic Cancer Registry of Côte d'Or, Georges-François Leclerc Cancer Centre, UNICANCER, Dijon, France. ${ }^{5}$ Departement of Statistics, Computer Science and Applications (DISIA), University of Florence, Florence, Italy. 
Received: 27 September 2019 Accepted: 11 May 2020 Published online: 20 May 2020

\section{References}

1. Ferlay J, Colombet M, Soerjomataram I, Dyba T, Randi G, Bettio M, Gavin A, Visser O, Bray F. Cancer incidence and mortality patterns in Europe: estimates for 40 countries and 25 major cancers in 2018. Eur J Cancer. 2018;103:356-87.

2. Kamińska M, Ciszewski T, Łopacka-Szatan K, Miotła P, Starosławska E. Breast cancer risk factors. Prz Menopauzalny. 2015;14(3):196-202.

3. Brown KF, Rumgay H, Dunlop C, Ryan M, Quartly F, Cox A, Deas A, EllissBrookes L, Gavin A, Hounsome L, Huws D, Ormiston-Smith N, Shelton J, White C, Parkin DM. The fraction of cancer attributable to modifiable risk factors in England, Wales, Scotland, Northern Ireland, and the United Kingdom in 2015. Br J Cancer. 2018;118(8):1130-41.

4. Apostolou P, Fostira F. Hereditary breast Cancer: the era of new susceptibility genes. Biomed Res Int. 2013;2013:747318.

5. Mouly TA, Toms LL. Breast cancer and persistent organic pollutants (excluding DDT): a systematic literature review. Environ Sci Pollut Res Int. 2016;23(22):22385-407.

6. Alaee M, Arias P, Sjödin A, Bergman A. An overview of commercially used brominated flame retardants, their applications, their use patterns in different countries/regions and possible modes of release. Environ Int. 2003; 29(6):683-9.

7. COUNCIL DIRECTIVE of 27 July 1976 on the approximation of the laws, regulations and administrative provisions of the Member States relating to restrictions on the marketing and use of certain dangerous substances and preparations (76/769/EEC) Available on: https://eur-lex.europa.eu/legalcontent/EN/TXT/PDF/?uri=CELEX:31976L0769\&from=en.

8. DIRECTIVE 2003/11/EC OF THE EUROPEAN PARLIAMENT AND OF THE COUNCIL of 6 February 2003 Amending for the 24th time Council Directive 76/769/EEC relating to restrictions on the marketing and use of certain dangerous substances and preparations (pentabromodiphenyl ether, octabromodiphenyl ether). Available on https://op.europa.eu/en/ publication-detail/-/publication/3a8d2aa2-2d34-4bec-bef2-3f45e17ab09b/ language-en.

9. Yu G, Bu Q, Cao Z, Du X, Xia J, Wu M, Huang J. Brominated flame retardants (BFRs): A review on environmental contamination in China. Chemosphere. 2016;150:479-90.

10. Fromme H, Becher $\mathrm{G}$, Hilger B, Völkel W. Brominated flame retardants exposure and risk assessment for the general population. Int J Hyg Environ Health. 2016;219(1):1-23.

11. Kim YR, Harden FA, Toms LM, Norman RE. Health consequences of exposure to brominated flame retardants: a systematic review. Chemosphere. 2014;106:1-19.

12. IARC Monographs Priorities Group. Advisory Group recommendations on priorities for the IARC Monographs. Lancet Oncol. 2019;20(6):763-4.

13. Bergman A, Heindel JJ, Kasten T, Kidd KA, Jobling S, Neira M, Zoeller RT, Becher G, Bjerregaard P, Bornman R, Brandt I, Kortenkamp A, Muir D, Drisse MN, Ochieng R, Skakkebaek NE, Byléhn AS, Iguchi T, Toppari J, Woodruff TJ, et al. The impact of endocrine disruption: a consensus statement on the state of the science. Environ Health Perspect. 2013;121(4):A104-6.

14. Hurley S, Goldberg D, Park JS, Petreas M, Bernstein L, Anton-Culver H, Neuhausen SL, Nelson DO, Reynolds P. A breast cancer case-control study of polybrominated diphenyl ether (PBDE) serum levels among California women. Environ Int. 2019;127:412-9.

15. Holmes AK, Koller KR, Kieszak SM, Sjodin A, Calafat AM, Sacco FD, Varner DW, Lanier AP, Rubin $\mathrm{CH}$. Case-control study of breast cancer and exposure to synthetic environmental chemicals among Alaska native women. Int J Circumpolar Health. 2014;73:10.3402.

16. Hurley S, Reynolds P, Goldberg D, Nelson DO, Jeffrey SS, Petreas M. Adipose levels of polybrominated diphenyl ethers and risk of breast cancer. Breast Cancer Res Treat. 2011;129(2):505-11.

17. He Y, Peng L, Zhang W, Liu C, Yang Q, Zheng S, Bao M, Huang Y, Wu K. Adipose tissue levels of polybrominated diphenyl ethers and breast cancer risk in Chinese women: a case-control study. Environ Res. 2018;167:160-8.

18. Terrell ML, Rosenblatt KA, Wirth J, Cameron LL, Marcus M. Breast cancer among women in Michigan following exposure to brominated flame retardants. Occup Environ Med. 2016;73(8):564-7.

19. Henderson AK, Rosen D, Miller GL, Figgs LW, Zahm SH, Sieber SM, Rothman $\mathrm{N}$, Humphrey HE, Sinks T. Breast cancer among women exposed to polybrominated biphenyls. Epidemiology. 1995;6:544-6.
20. Hoque A, Sigurdson AJ, Burau KD, et al. Cancer among a Michigan cohort exposed to polybrominated biphenyls in 1973. Epidemiology. 1998;9:373-8.

21. Clavel-Chapelon F. E3N study group. Cohort profile: the French E3N cohort study. Int J Epidemiol. 2015;44:801-9.

22. Mancini FR, Cano-Sancho G, Gambaretti J, Marchand P, Boutron-Ruault MC, Severi G, Arveux P, Antignac JP, Kvaskoff M. Perfluorinated alkylated substances serum concentration and breast cancer risk: evidence from a nested case-control study in the French E3N cohort. Int J Cancer. 2019;22 [Epub ahead of print].

23. Cariou R, Antignac JP, Marchand P, Berrebi A, Zalko D, Andre F, Le Bizec B. New multiresidue analytical method dedicated to trace level measurement of brominated flame retardants in human biological matrices. J Chromatogr A. 2005;1100:144-52.

24. Ploteau S, Cano-Sancho G, Volteau C, Legrand A, Venisseau A, Vacher V, Marchand P, Le Bizec B, Antignac JP. Associations between internal exposure levels of persistent organic pollutants in adipose tissue and deep infiltrating endometriosis with or without concurrent ovarian endometrioma. Environ Int. 2017;108:195-203.

25. Udesky JO, Dodson RE, Perovich LJ, Rudel RA. Wrangling environmental exposure data: guidance for getting the best information from your laboratory measurements. Environ Health. 2019;18(1):99.

26. Akins, J.R.; Waldrep, K.; Bernert, J.T., Jr. The estimation of total serum lipids by a completely enzymatic 'summation' method. Clinica chimica acta; international journal of clinical chemistry 1989;184:219-226.

27. Schisterman EF, Whitcomb BW, Louis GM, Louis TA. Lipid adjustment in the analysis of environmental contaminants and human health risks. Environ Health Perspect. 2005;113(7):853-7.

28. Edefonti V, Decarli A, La Vecchia C, Bosetti C, Randi G, Franceschi S, Dal Maso L, Ferraroni M. Nutrient dietary patterns and the risk of breast and ovarian cancers. Int J Cancer. 2008;122(3):609-13.

29. Tehard B, Kaaks R, Clavel-Chapelon F. Body silhouette, menstrual function at adolescence and breast cancer risk in the E3N cohort study. Br J Cancer. 2005;92(11):2042-8.

30. Jackson E, Shoemaker R, Larian N, Cassis L. Adipose tissue as a site of toxin accumulation. Compr Physiol. 2017;7(4):1085-135.

31. Sorensen TI, Stunkard AJ, Teasdale TW, Higgins MW. The accuracy of reports of weight: children's recall of their parents' weights 15 years earlier. Int J Obes. 1983;7:115-22

32. Sjödin A, Wong LY, Jones RS, Park A, Zhang Y, Hodge C, Dipietro E, McClure C, Turner W, Needham LL, Patterson DG Jr. Serum concentrations of polybrominated diphenyl ethers (PBDEs) and polybrominated biphenyl (PBB) in the United States population: 2003-2004. Environ Sci Technol. 2008:42(4):1377-84.

33. Santé publique France. Imprégnation de la population française par les retardateurs de flamme bromés. Programme national de biosurveillance, Esteban 2014-2016. Santé publique France, septembre 2019. 61 p. Available on: www.santepubliquefrance.fr.

34. Li Y, Millikan RC, Bell DA, Cui L, Tse CK, Newman B, Conway K. Polychlorinated biphenyls, cytochrome P450 1A1 (CYP1A1) polymorphisms, and breast cancer risk among African American women and white women in North Carolina: a population-based case-control study. Breast Cancer Res. 2005;7(1):R12-8 Epub 2004 Oct 22.

35. LV QX, Wang W, Li XH, Yu L, Zhang Y, Tian Y. Polychlorinated biphenyls and polybrominated biphenyl ethers in adipose tissue and matched serum from an E-waste recycling area (Wenling, China). Environ Poll (Barking, Essex: 1987). 2015;199:219-26.

36. Cano-Sancho G, Labrune L, Ploteau S, Marchand P, Le Bizec B, Antignac JP. The challenging use and interpretation of circulating biomarkers of exposure to persistent organic pollutants in environmental health: comparison of lipid adjustment approaches in a case study related to endometriosis. Chemosphere. 2018;200:388-96.

37. Cao L-Y, Ren X-M, Yang Y, Wan B, Guo L-H, Chen D, Fan Y. Hydroxylated Polybrominated Diphenyl ethers exert estrogenic effects via non-genomic $G$ protein-coupled estrogen receptor mediated pathways. Environ Health Perspect. 2018;126:057005.

38. La Merrill M, Emond C, Kim MJ, Antignac JP, Le Bizec B, Clément K, Birnbaum LS, Barouki R. Toxicological function of adipose tissue: focus on persistent organic pollutants. Environ Health Perspect. 2013;121(2):162-9.

\section{Publisher's Note}

Springer Nature remains neutral with regard to jurisdictional claims in published maps and institutional affiliations. 